\title{
Can Robots Help Working Parents with Childcare? Optimizing Childcare Functions for Different Parenting Characteristics
}

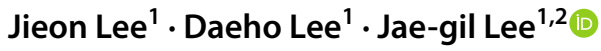 \\ Accepted: 23 March 2021 / Published online: 5 April 2021 \\ (c) The Author(s), under exclusive licence to Springer Nature B.V. 2021
}

\begin{abstract}
Is it true that parents always prioritize educational effectiveness when selecting childcare services? The current study identified the potential requirements of dual-income parents toward social robots' diverse childcare functions (e.g., socialization, education, entertainment, and consultation). The results revealed that parental attitudes toward robots were made more positive by all the childcare functions of robots except for their educational features. Furthermore, parents' expectations of childcare functions varied based on their parenting characteristics. Spectral clustering analysis identified distinctive parenting styles (e.g., family-oriented, work-oriented, noninterventional, and dominant), and multigroup structural equation modeling suggested that the impact of robots' socialization function was significant in all parent groups, while other childcare functions exerted limited influence according to specific parenting styles. In addition, children's characteristics were found to alter parents' preferences for each childcare function. These results offer practical implications for the early adoption of childcare robots through predetermining parents' acceptability based on their specific parenting characteristics.
\end{abstract}

Keywords Social robots · Childcare robots · Children-robot interaction · User experience

\section{Introduction}

Today, robots provide people with mental and psychological aid by performing actions such as talking to them in daily life, exchanging information, and sharing intimate feelings. These social robots are physically embodied artificial agents designed to display socially appropriate and meaningful behaviors to interact and communicate naturally with humans [1-3]; thus, they are capable of interacting with human users to ameliorate the quality of their daily life. Recent advancements in machine learning and artificial intelligence technologies have sparked active exploration of areas where robots' social capabilities can be applied. For example, studies on children-robot interaction have suggested ways in which effective learning can be triggered by

Jae-gil Lee

politejake.lee@gmail.com

1 Department of Interaction Science, Sungkyunkwan University, 25-2 Sungkyunwan-ro, Jongno-gu, Seoul 03063, Republic of Korea

2 Media Effects Research Laboratory, Donald P. Bellisario College of Communications, The Pennsylvania State University, University Park, PA 16803, USA employing the social capabilities of robots to develop robotgenerated learning content in classroom environments [4-6]. In addition, with their interaction capabilities, social robots can enhance the persuasive quality of conveyed messages [7, 8], reduce stress, and provide emotional relief for children [9], going beyond mere educational purposes. Moreover, another line of research has explored the use of robots to conduct wide-ranging activities for parenting, including parent-child communication [10], entertainment [11-13], and the maintenance of children's behavioral records [14]. Given the benefits they can offer, social robots are expected to play various roles in children's development.

Among the many application areas of social robots in children's development, the present study focused on using social robots to support parenting in the home environment. Of special interest are dual-income parents, as they are expected to be early adopters of childcare robots. Such parents are concerned that the insufficient time they have to devote to parenting tasks may hinder the cognitive and emotional development of their children $[15,16]$. Therefore, dual-income parents endeavor to provide superior social experiences to their children [16, 17, 81], and utilize alternative parenting services more keenly [15]. For these reasons, social robots can be designed to bridge the gaps in 
nurturing that confront dual-income parents to satisfy their parental demands $[18,19]$. These robots can potentially support many parenting functions as well as compensate for the paucity of emotional interaction experiences for children of dual-income parents who find it difficult to focus on childcare.

Despite the high interest in children-robot interaction, relatively little attention has been paid to the use of childcare robots in home settings. Relevant studies have mainly focused on how robots can effectively provide educational content to improve learning outcomes [6]. Consequently, parents have attracted little attention despite being the primary decision-makers for their children. Since childcare robots are expected to be used in family home environments, an investigation of parental needs regarding childcare robots will provide critical insights. Moreover, parents' preferences and expectations of childcare robots are likely to vary across families, because each family has different parenting styles and childcare environments. Thus, the differences between families should be considered when designing childcare robots. Lastly, although childcare social robots can offer a variety of functions, little is known about the relative importance among those functions. By comparing numerous functions simultaneously, specific functions that exercise a greater impact on shaping a positive attitude can be more accurately ascertained.

In light of the aforementioned discussion, the present study proposed the following general research question to produce development guidelines for childcare robots that support parenting.

General Research Question For dual-income parents with different parenting characteristics, what are the differences in their preferences for robots' childcare functions?

To address this research question, the present study first explored dual-income parents' needs in childcare. Then, it suggested a range of childcare-support functions of robots based on the identified parental needs. Next, the study examined the presumption that these childcare features can elicit positive responses from parents toward such robots, and compared the relative importance among the parentingsupport functions. Finally, the present study investigated the differences in parents' preferences for robots' childcare functions based on their different parenting characteristics.

\section{Related Works}

\subsection{Social Robots for Childcare Service}

Due to existing parenting challenges, childcare robots have attracted significant scholarly attention. Robots with various interaction techniques, including touch interfaces, facial recognition, and natural conversation, are expected to play numerous childcare roles; they can deliver messages between parents and children, and they can be playmates, conversation partners, and tutors [20, 21]. In addition, a line of studies has suggested ways to support parenting, such as education, entertainment, and the building of social bonds with children. As for educational application, a carereceiving robot, for instance, enables a child to learn through teaching the robot English vocabulary and how to do handwriting, as opposed to the child being taught by the robot $[22,23]$; furthermore, in-home robots can improve children's motivation and interest in learning [24, 25]. In addition to providing academic aid, robots are used to teach children how to choose healthy diets [26]. Regarding entertainment, home telepresence robots support childcare; one such robot plays with children while parents are doing housework and, through a head-mounted display, they are able to remotely take care of their children simultaneously [18]. Another telepresence robot is teleoperated by adults to interact with their babies/toddlers [27]. Childcare robots can also be used as tools for building social skills. These socially interactive robots can assist children with autism spectrum disorders [28] by diagnosing and understanding autism and helping children with autism to develop their social skills [29]. Moreover, children can establish social bonds by interacting with robots that act as friends and mentors to them [9].

While existing works on childcare robots have mainly focused on children's perceptions of the robots, their parents have attracted relatively little attention. Indeed, parents are the main subject of parenting, and parenting is a journey involving both parents and children; thus, parents must be considered in the design of childcare robot services. Lin et al. [30] found that parents' acceptance of childcare robots requires not only simple functions but also profound interaction quality provided by the robot; therefore, they suggested that a more in-depth exploration for latent factors would be necessary. This perspective is particularly critical because children are highly influenced by their parents, and parental attitudes toward robots are important in children's use of robots [31]. For example, parents who consider reading books together to be crucial for social bonding might be worried about using a storytelling robot [30], and they would likely not allow the robot to read books to their children. Such a negative attitude toward a robot would have a negative effect on the children's attitudes toward that robot [31]. Thus, it is essential to understand the needs of parents and what functions they desire in childcare robots, as well as for parents to have a positive attitude toward such robots.

\subsection{Parents' Childcare Needs}

According to papers on parents' employment and children's well-being, many working parents are concerned about the lack of time they spend with their children as well as 
housework, which might negatively affect children's affective and cognitive development [32,33]. In particular, social interaction time spent between parents and children on education and conversation, which require high concentration and participation from both parties, positively predicts children's social and affective development. Parent-child interactions encourage primary social learning. Parents' educational activities for their children, such as reading books, require active verbal communication; therefore, reading books with parents improves not only the child's cognitive development but also their emotional development. In the same vein, parents and children spending time together on homework, play, and housework has a positive effect on children's social development—even if these are not direct educational activities-because they require high participation as well as effective communication from both parties $[16,17]$. On the other hand, childcare time with little parent-child interaction was found to be nonsignificant or even negative for a child's development [34].

Based on the aforementioned discussion, it can be concluded that providing children with rich social and communication experiences is more effective than securing maximum parenting time when establishing parenting strategies for dual-income parents. Providing children with quality social experiences is surely seen as a crucial goal in raising them. Indeed, dual-income parents tend to reduce household chores and personal duties [81] to maintain quality social interaction time with their children [16]. In other words, dual-income parents attempt to increase the amount of quality time spent with their children, and compensate for insufficient parenting time [35] with parenting quality [16]. In addition, parents encourage children to actively interact with social partners such as friends, teachers, relatives, and companion animals to form social relationships [33] because they value socialization in childcare settings.

Parents' needs in raising their children predict how childcare robots will be used in home environments. Kwak et al. [19] conducted in-depth interviews with dual- and single-income parents and identified six primary childcare requirements for childcare robots: education, entertainment, communication, emotional response, scheduling, and monitoring. Their results revealed that dual- and singleincome families exhibited different preferences for childcare robots. Working parents required scheduling because they have time restrictions when managing childcare and housework. By contrast, for single-income families, an educational application appeared to be the most critical aspect. Moreover, both family types considered entertainment and monitoring of their children's physical and psychological activities as important. In summary, parents expect childcare robots to provide social experience, educational, and entertainment content. In addition, such robots must support parents through providing sufficient information about their children's development.

\section{Hypothesis Statements}

Based on the discussion in the previous section on parents' needs in childcare, the present study suggested the following childcare functions of social robots: socialization, education, entertainment, and expert counseling. Figure 1 presents the proposed model of this study and describes the relationships between parents' expectations of childcare functions, their attitude toward childcare robots, and their willingness to seek more detailed knowledge.

According to use and gratification $(U \& G)$ theory, endusers choose and consume media technologies that satisfy their needs [36]. Dual-income parents are highly aware of their parenting needs and actively engage in exploring and employing services that can satisfy their requirements. These qualities are congruent with the user characteristics assumed by $U \& G$ theory. The U\&G framework explains how the needs of end-users promote media consumption across the spectrum-from traditional media to new media $[37,38]$. The flexible methodology offered by the U\&G perspective also provides grounding for research on state-ofthe-art technical features of emergent media devices. Hence, it allows for the investigation of the ways in which devices such as social robots can influence the psychological needs of users and how they may shape behaviors with respect to technology use [39]. In this manner, state-of-the-art

Fig. 1 Proposed research model

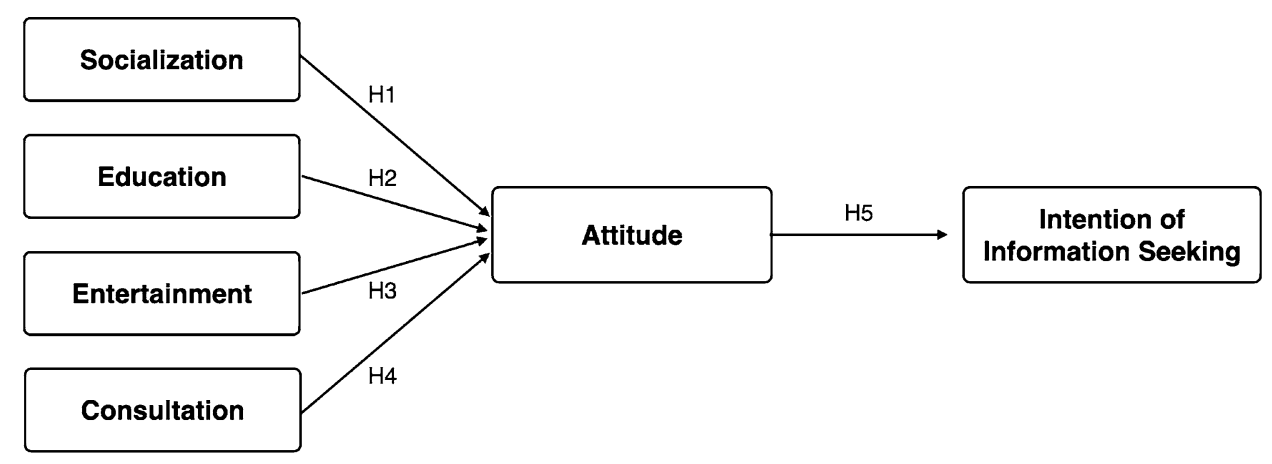


technology can generate new needs and expectations in users, and services utilizing media technology can be designed to satisfy the distinct needs of their target users.

Substantial research endeavors on the subject of $U \& G$ and on the technology acceptance model (TAM) have evidenced that the attitudes and perceptions of users toward specified media and technology were positively influenced by user expectations that they would satisfy their needs [40-42]. Consequently, a more favorable parental attitude is expected to be generated toward childcare robots if parents have high expectations from the parenting-support functions of robots.

\subsection{Parental Expectations from the Socialization Function of Robots}

Through their imaginative interactive capabilities, social robots encourage children to engage actively in communication $[43,44]$ and generate satisfactory personal relationships with children [9]. Social robots can consult with children about their concerns [45], and if necessary, they can also offer children advice that adheres to the demands of social ethics. Childcare robots can also be used to socialize children and to instill socially desirable behavior in them, which is a parenting issue of particular concern for dualincome families. Accordingly, we proposed the following hypothesis:

Hypothesis 1 ( $\mathrm{H} 1)$ Double-income parents will form a favorable attitude toward a robot based on their expectations of its socialization function for their children.

\subsection{Parental Expectations from the Education Function of Robots}

Social robots are likely to become one of the most advantageous educational tools along with writing supplies and computers [6]. Compared with virtual agents displayed only on a screen, robots that have physical bodies have been reported to enhance the effectiveness of educational content by encouraging participation from learners $[5,6,46]$. The educational content programmed into childcare robots boosts children's concentration, and thus, tends to generate superior learning effects compared with traditional video and image-based educational material. If parenting robots can provide high-quality educational content, dual-income parents will probably use robots to help their children achieve better academic outcomes [19]. Accordingly, we proposed the following hypothesis:

Hypothesis 2 ( $\mathrm{H} 2)$ Double-income parents will form a favorable attitude toward a robot based on their expectations of its educational utility for their children.

\subsection{Parental Expectations from the Entertainment Function of Robots}

Physically formed robots can interact tangibly with children to produce a dynamic and authentic recreation environment that is more interesting than the mere playing of entertainment content. Robots can interact directly with children by performing actions such as dancing [13] or by playing board games with them [12]. Furthermore, parents desired childcare robots to be programmed with the ability to play with children while they are busy with household chores or when they desire some personal time [19]. According to the relationship between the expectations and attitudes of dualincome parents with regard to the entertainment function of robots, this study proposed the following hypothesis:

Hypothesis $3(\mathrm{H} 3)$ Double-income parents will form a favorable attitude toward a robot based on their expectations of its entertainment function for their children.

\subsection{Parental Expectations from the Consultation Expertise and Advisory Functions of Robots}

Parents value the advice of experienced childcare professionals [33] and will appreciate robots that can deliver the recommendations of expert consultants to their children [19]. Through their capability for direct interaction, childcare robots can also encourage children to speak freely about their concerns [45]. Further, parenting robots can record any unusual behavior displayed by children for expert reference, and parents responded positively to this recording function [14]. Therefore, parenting robots can act as beneficial tools for the collection of behavioral data on children, and can also help to deliver these data to specialist counseling agencies, enabling parents to obtain appropriate professional advice. Accordingly, the fourth hypothesis was formulated as follows:

Hypothesis 4 (H4) Double-income parents will form a favorable attitude toward a robot depending on their expectations from its counseling expertise and advisory functions for their children.

\subsection{Parental Intentions to Seek Information}

An individual's intentions toward a specific behavior are generally considered pivotal to the actual performance of that behavior [47, 82]. A person's attitude toward a particular behavior is a key contributor to the shaping of his or her personal intentions, an assertion that has been validated by a series of conceptual frameworks including the theory of reasoned action [82], the theory of planned behavior [47], and the TAM [48]. The TAM identifies the process through 
which users accept and utilize novel technologies. Thus, positive parental attitudes toward childcare robots are likely to contribute to parental intentions to accept and use them. The present study characterized the behavioral intentions of parents to adopt childcare robots through their plans to research information about the robots in more detail. This attribute was specified because of the absence of viable childcare robots in the current marketplace. Since parents cannot yet directly or indirectly experience the usage of social robots, their iteration of future information-seeking intent could provide a more accurate and practical result regarding their prospective acceptance and utilization of robots that support parenting tasks. Employing this rationale, the relationship between parental attitudes toward childcare robots and the intentions of parents to seek additional information about the technology was postulated in the following hypothesis:

Hypothesis 5 (H5) The positive attitude of dual-income parents toward robots will enhance their intentions to seek more detailed information about robots.

\subsection{How Parenting Characteristics Influence Functional Expectations}

\subsubsection{Influence of Parenting Styles}

In addition to the aforementioned hypotheses about the functions of childcare robots, the current study also investigated whether parental preferences for individual functions of social robots would vary according to the divergent parenting styles exhibited by dual-income parents. In fact, both single- and dual-income parents, whose parenting environments differ, prioritize the desired parenting functions of robots in contrasting ways. The ultimate desire of doubleincome parents is to efficiently manage schedules and optimally utilize their insufficient parenting time. On the other hand, single-income parents find the educational functions of robots most crucial [19]. Similarly, if the impact of specific parenting styles on parents' functional preferences for robots can be confirmed, social robot makers will be able to offer customized functions for parenting robots for specific households. Therefore, validating the correlations between particular parenting styles and parental preferences for each of the four aforementioned functions of childcare robots is worthwhile.

Darling and Steinberg [49] defined parenting style as "a constellation of attitudes toward the child that are communicated to the child and that, taken together, create an emotional climate in which the parent's behaviors are expressed." Long-standing interest in different parenting styles has been primarily aimed at predicting child development, and researchers have sought to identify parental behaviors that can predict child development [83]. Currently, the method of
Baumrind is the most widely used categorization model [50, 51]. Baumrind used two dimensions, namely demandingness and responsiveness, and derived a four-fold classification of parenting styles: authoritarian, permissive, authoritative, and rejecting-neglecting. Based on existing discussions for categorizing parental behaviors, the present study used parenting time as the most important concept for clustering the parenting style of dual-income families. Such families have been increasing in number recently, and they typically lack time for parenting compared with single-income families $[16,19]$. A recent study found that the average number of working hours for a dual-income couple is 41 per week, with $2.5 \mathrm{~h}$ to commute, for a total of $43.5 \mathrm{~h}$ outside the home, while their children spend $30 \mathrm{~h}$ a week at school on average. As a result, these children spend an average of $13.5 \mathrm{~h}$ alone each week [52]. Indeed, according to existing studies, time investment in children has a positive effect on child rearing and the quality of life of children [53-56]. For dual-income parents who work for a long time, it is difficult for them to secure time with their children, meaning they cannot participate in various parenting activities. Thus, the choices parents make to compensate for their lack of childcare, including their use of time and childcare services, can be essential factors for categorizing parenting styles. In this context, this study developed the following research question to probe the relationships between parenting styles and parental preferences for specific utilities served by childcare robots:

Research Question 1 ( $R Q$ 1) Do variations in the time devoted by parents to childcare and differences in duration of parental absence, along with the use of in-home childcare services, induce dissimilar parental attitudes toward robots' childcare functions?

\subsubsection{Influence of Children's Characteristics}

Children's unique characteristics, such as their age and sibling status, can also alter parents' social robot acceptance. Children exhibit distinct developmental patterns as they grow, and thus, parents may prioritize childcare activities differently. Indeed, theoretical discussions on children's sociocognitive development have argued that parents should emphasize appropriate developmental tasks for their children in accordance with their stages of development [57]. For example, parents of early-childhood children are recommended to encourage their children to explore the world on their own, whereas parents of mid-childhood children need to encourage their children to feel confident in their abilities. That is, in the process of their sociocognitive development, children first learn how to act with their own will before being able to evaluate the consequences of their own actions. In addition, children's developmental status influences their social interaction style. A series of empirical studies have consistently reported that younger children are relatively 
passive in social processes, whereas older children are active [58-61]. Regarding this tendency for passive interaction of young children, Saarni [62] explained that young children suppress emotional expressions because they are immature in how they express emotions, and therefore, they worry that incorrect expression will lead to negative consequences.

In addition, children's developmental status has a critical influence on their interaction with robots. Studies have reported that young children are more sensitive to the sociality of robots [63, 88]. For example, young children under the age of 9 years perceived robots as social beings only through their appearance, whereas older children perceived robots as social beings through more sophisticated interactions [64]. Similarly, another study indicated that children aged 6 to 7 years exhibited favorable perceptions regardless of the robot's personality and interaction style [65]. However, the same study also confirmed that children between the ages of 8 and 11 years could distinguish the detailed social characteristics of robots. Children aged between 8 and 14 years, relatively older in this context, did not exhibit significant differences in the shaping of their attitudes and perceptions of robots [66]. In other words, as Shahid [67] indicated, younger children are more likely to simply enjoy interacting with robots rather than assessing their social capabilities in depth. Despite these prior studies, empirical evidence and theoretical discussions remain lacking, making it difficult to accurately predict the impact of children's age on their acceptance of childcare robots. Therefore, to explore how parents' preferences for various parenting functions of robots vary with the age of children, this study developed the following research question:

Research Question 2 ( $R Q 2$ ) How does children's childhood stage change their parents' attitudes toward robots' childcare functions?

Another child-oriented factor that determines parents' attitude toward a childcare robot is sibling status. Siblings are essential partners in social interaction, play, and mutual learning, and thus, they have a great influence on children's growth. A pervasive stereotype exists that children without siblings—only children — are narcissistic, arrogant, and self-righteous; therefore, parents of only children are concerned about the appropriate emotional development of their child [84, 85]. Indeed, many studies have presented counterarguments to this stereotype; for example, children's social development is determined by their parents' interests and quality social experiences [68], and an only child may even surpass other children with siblings in social development because they can monopolize on social interaction with their parents $[69,70]$. However, the subjects of the present study are dual-income parents, who are generally concerned about insufficient interaction with their children. Despite the aforementioned counterevidence, concerns about their child's proper social development can be a very real problem for these parents. Therefore, to explore the difference between parents with a single child and parents with multiple children, this study proposed the following research question:

Research Question 3 (RQ 3) What are the differences in parents' attitudes toward robots' childcare functions between single-child and multi-child families?

\section{Data}

\subsection{Measurements}

The current study examined the childcare needs of parents by conducting a thorough examination to test the proposed research model and hypotheses. It created questionnaire items on parental expectations for childcare functions of social robots because these features have not yet been reviewed by researchers. Previous studies have adopted two measurement variables, attitude toward robots [71] and intention to search information [72]. An electronic questionnaire was administered to respondents, who were required to indicate their degree of agreement with each item on a five-point Likert scale $(1=$ strongly disagree, $5=$ strongly agree). The whole items are provided in Appendix I.

\subsection{Respondents}

The developed questionnaire was distributed to 624 double-income families in South Korea. Table 1 presents the demographic characteristics of the respondents. All respondents were mothers $(N=351)$ or fathers $(N=273)$ raising a child or children aged between 3 and 12 years. To explore the research questions regarding children's age and sibling status, children's characteristics were considered when gathering data. Of the 624 families, 204 parents had an early-childhood child (aged 3-7 years), 210 parents had a middle-childhood child (aged 8-12 years), and 210 parents were raising two or more children (aged 3-12 years). In this study, the early-childhood children were preschoolers, and middle-childhood children were schoolers, as the childhood groups were determined by the age that a child enters elementary school in Korea ( 8 years of age in Korean age corresponds to 6-7 years of age by Western measurements). The majority of respondents $(N=506)$ were full-time employees, and $17.8 \%$ of the participating parents $(N=111)$ denoted family units in which one parent worked full-time and the other was a part-time employee. The remaining seven parents were having temporal parental leave or working from home. We included these family units in the analysis because they still lacked a full-time guardian for their children. Even though only one of the parents worked full-time at their workplace, part-time and home-working parents in this study spent more than six hours a day working on average, and 
Table 1 Demographic characteristics of respondents and their children

\begin{tabular}{lllrc}
\hline Group & Characteristics & Details & Frequency $(N)$ & Percentage $(\%)$ \\
\hline Parents & Gender & Male & 273 & 43.8 \\
& \multirow{2}{*}{ Age } & Female & 351 & 56.3 \\
& & $50-29$ & 5 & 0.8 \\
& & $30-39$ & 308 & 49.4 \\
& \multirow{4}{*}{ Employment Type } & Both Full-Time Employees & 506 & 49.7 \\
& & Full and Part-Time Employees & 111 & 0.2 \\
& & Others & 7 & 81.1 \\
Children & Single Child & Early Childhood (3-7) & 204 & 17.8 \\
& & Middle Childhood (8-12) & 210 & 1.1 \\
& \multirow{2}{*}{ Multiple Children } & Aged between 3-12 & 210 & 32.6 \\
& & & 33.7 \\
\hline
\end{tabular}

they also had nearly two hours of absence in parenting. The respondents were aged between 27 and 50 years, with most being in their 30 and $40 \mathrm{~s}$.

\subsection{Data Validation}

An exploratory factor analysis was conducted on the 15 expectation items using principal component analysis. An orthogonal Varimax rotation method was also employed to identify the underlying structure of parental expectations from the discrete childcare functions of robots (see Table 2). As anticipated, the factor analysis extracted the four predetermined expectation attributes relating to the childcare functions of robots. These functions were labeled entertainment, education, socialization, and expert consultation. In addition, the internal consistency of each of the identified factors was calculated using Cronbach's alpha, and the reliability values of all expectation categories were found to be above the adequate level.

The convergent and discriminant validity of the measured data were assessed through a comparison of the internal consistency of each variable and its correlations with the other variables. Table 3 demonstrates the average variance extracted (AVE) values of each latent variable as well as the inter-construct correlations. The square root of the AVE of each latent variable should be higher than its correlation value with any other constructs [73]. As the results in Table 3 indicate, the latent variables were reliable and valid.
Table 2 Results of the exploratory factor analysis of parental expectations of robot features

\begin{tabular}{lllll}
\hline Items & Factor Loadings & & \\
\cline { 2 - 5 } & $\begin{array}{l}\text { Expectation of Enter- } \\
\text { tainment }(\alpha=.891)\end{array}$ & $\begin{array}{l}\text { Expectation of } \\
\text { Socialization } \\
(\alpha=.860)\end{array}$ & $\begin{array}{l}\text { Expectation of Edu- } \\
\text { cation }(\alpha=.813)\end{array}$ & $\begin{array}{l}\text { Expectation of } \\
\text { Expert Consultation } \\
(\alpha=.855)\end{array}$ \\
\hline Exp_Ent 1 & .854 & & & \\
Exp_Ent 2 & .815 & & & \\
Exp_Ent 3 & .815 & & & \\
Exp_Ent 4 & .700 & & & \\
Exp_Soc 1 & & .827 & & \\
Exp_Soc 2 & & .820 & .821 & .718 \\
Exp_Soc 3 & & .765 & .652 & .830 \\
Exp_Soc 4 & & .675 & & .807 \\
Exp_Edu 1 & & & & .783 \\
Exp_Edu 2 & & & & \\
Exp_Edu 3 & & & & \\
Exp_Edu 4 & & & & \\
Exp_Con 1 & & & & \\
Exp_Con 2 & & & & \\
Exp_Con 3 & & & & \\
\hline
\end{tabular}




\section{Results}

\subsection{Hypotheses Testing}

The present study employed structural equation modeling (SEM) to test the hypotheses and answer the research question. The statistical indices relating to the fit of the proposed research model evidenced that the chi-square $\left(\chi^{2}\right)$ indicator for the model was significant at $\chi^{2}(198, N=624)=723.844$, $p<0.001$, and the $\chi^{2} /$ degrees of freedom (df) ratio was 3.66. In terms of other indices, the root mean square error of approximation (RMSEA) was computed at 0.065 , the incremental fit index (IFI) was 0.941, and the comparative fit index (CFI) was 0.941. These results indicated acceptable fitness of the proposed model.

Figure 2 outlines the estimation results for the SEM analysis of the proposed model. As demonstrated in the figure, except for expectations of the education function, parental expectations of varied childcare functions in robots predicted their positive attitudes toward robots. The results also evidenced that the more positive a parent's attitude toward robots, the stronger that parent's reported intention to seek additional information about robots.

Table 4 presents the results obtained from testing this study's hypotheses. It is evidenced that parental expectations from the socialization feature $(H I)$ of robots exerted a positive effect on their attitudes toward childcare robots. Similarly, aspirations for entertainment (H3) and expert consultation ( $H 4)$ facilities predicted more positive parental attitudes. However, the findings did not demonstrate a positive association between hopes for educational features (H2) in robots and positive parental attitudes toward them. Given the numerous studies on the educational effectiveness of social robots, this surprising result must be further

Table 3 Test results of convergent and discriminant validity

\begin{tabular}{|c|c|c|c|c|c|c|c|c|}
\hline Variables & AVE & C. $\mathrm{R}$ & Socialization & Education & Entertainment & $\begin{array}{l}\text { Expert con- } \\
\text { sultation }\end{array}$ & Attitude & $\begin{array}{l}\text { Informa- } \\
\text { tion seek- } \\
\text { ing }\end{array}$ \\
\hline Socialization & 0.720 & 0.910 & 0.849 & & & & & \\
\hline Education & 0.658 & 0.884 & $.576^{* *}$ & 0.811 & & & & \\
\hline Entertainment & 0.780 & 0.933 & $.497 * *$ & $.612 * *$ & 0.883 & & & \\
\hline Expert Consultation & 0.783 & 0.915 & $.477 * *$ & $.554 * *$ & $.532 * *$ & 0.885 & & \\
\hline Attitude & 0.805 & 0.943 & $.551^{* *}$ & $.462 * *$ & $.465^{* *}$ & $.466^{* *}$ & 0.897 & \\
\hline Information Seeking & 0.803 & 0.924 & $.520 * *$ & $.493 * *$ & $.463 * *$ & $.496 * *$ & $.685^{* *}$ & 0.896 \\
\hline
\end{tabular}

Diagonal elements represent the square root of the AVE; off-diagonal elements indicate correlations between constructs

Fig. 2 Estimation results relating to the proposed model

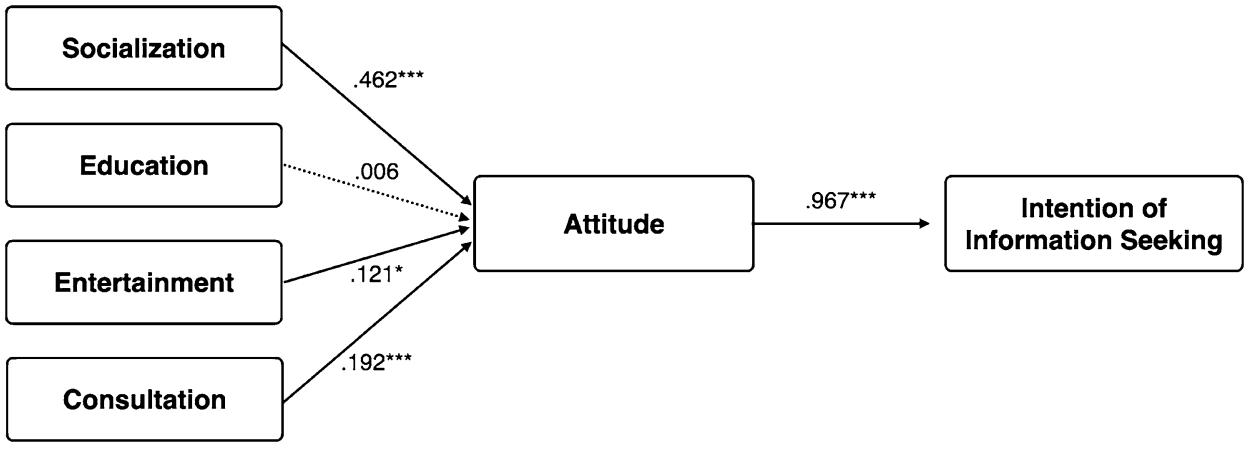

Table 4 Results of the testing of the hypotheses

\begin{tabular}{llllll}
\hline Hypotheses & $\begin{array}{l}\text { Standardized } \\
\text { estimate }\end{array}$ & $\begin{array}{l}\text { Unstandard- } \\
\text { ized estimate }\end{array}$ & S. E & C. R & P \\
\hline$H 1:$ Socialization $\rightarrow$ Attitude & 0.451 & 0.462 & 0.064 & 7.229 & $* * *$ \\
$H 2:$ Education $\rightarrow$ Attitude & 0.060 & 0.006 & 0.080 & 0.076 & .939 \\
$H 3:$ Entertainment $\rightarrow$ Attitude & 0.125 & 0.121 & 0.053 & 2.259 & .024 \\
$H 4:$ Expert Consultation $\rightarrow$ Attitude & 0.221 & 0.192 & 0.047 & 4.114 & $* * *$ \\
$H 5:$ Attitude $\rightarrow$ Intention to Seek Information & 0.783 & 0.967 & 0.055 & 17.431 & $* * *$ \\
\hline
\end{tabular}


scrutinized by ascertaining whether particular characteristics of diverse parenting styles hinder or facilitate parental desires regarding the educational features of robots. The next section discusses this issue further. The results validated $\mathrm{H} 1$, $\mathrm{H} 3$, and $\mathrm{H} 4$, but $\mathrm{H} 2$ was not supported. Moreover, $\mathrm{H} 5$ was confirmed in that parental attitudes toward childcare robots were ratified as significant predictors of their intentions to seek further information.

\subsection{Exploring Differences in Parenting Styles}

The general and specific research questions were proposed to explore how different parenting characteristics alter parents' preferences for robots' respective childcare functions. More specifically, RQ 1 queried whether different parenting styles generate divergent needs in childcare functions. To investigate the potential influences of parenting styles, the present study conducted clustering analysis to identify different parent groups and then compared them using a multigroup SEM analysis.

\subsubsection{Clustering Data by Distinctive Parenting Styles}

Spectral clustering analysis was conducted to categorize respondent parents according to their parenting styles. The spectral clustering technique classifies distinctive subgroups that are different from each other and that demonstrate similar in-group characteristics [74]. The analysis employed for the present study comprised three characteristics of parenting styles: the time parents expended on household chores, the time children spent alone (i.e., time that parents could not engage in childcare), and whether parents used supplemental in-home childcare services (e.g., a nanny, grandparents). As Table 5 exhibits, the analysis identified four subgroups of families with different parenting styles. The number of subgroups was determined using the eigengap heuristic method [74] and also with the $k$-fold cross-validation method, where the $k$ was 10 and the accuracy of the clustering result was estimated at $99.52 \%$ [75].

Parents designated to the first cluster spent more than four hours every day doing housework. Their commitment to parenting indicated that their children were not alone for too long despite the fact they utilized fewer in-home childcare services. Conversely, the parents in the second cluster spent less than an hour on housework, and these parents were relatively active in the use of in-home childcare support. The parents classified in the first two clusters were respectively labeled family-oriented and work-oriented. The parents allocated to the third and fourth clusters were similar in terms of the amount of time they expended on household chores: both groups of parents spent approximately two hours a day on housework. However, these parents differed in the time they could not engage in childcare and the ratios of their use of at-home childcare support. The parents assigned to the third group were comparatively reluctant to use extra childcare services; however, the fourth group demonstrated the highest use ratio for external services among all the clusters. More importantly, the children in the third group were left unsupervised for more than four hours per day, whereas those in the fourth group spent most of their time under adult supervision. The parents in the third group were thus named noninterfering, and those in the final cluster were called dominant. Noteworthy in this context is that while the number of children between these groups was similar, the ages of the children were not. The children of parents in the noninterference cluster (i.e., the third group) were relatively older $(M=9.479, S D=2.494)$ than the children of family-oriented parents $(M=7.218, S D=2.558)$, workoriented parents $(M=7.089, S D=2.411)$, and dominant parents $(M=7.160, S D=2.540)$.

\subsubsection{Influence of Parenting Styles on the Shaping of Parental Attitudes Toward Childcare Robots}

A multigroup SEM analysis was performed on the clustered groups of parents with discrete parenting styles. This analysis was aimed at investigating the potential changes in parental attitudes toward robots according to the variations in expectations exhibited by the four clusters. Before comparing the expectations that contributed to the shaping of parental attitudes, the inter-group measurement invariance was tested through nested comparisons using gradually constrained models (Table 7). The configural equivalence between the groups was supported by the overall fit indices of the model: $\chi^{2}(792)=1549.884, p<0.001, \chi^{2} /$ $\mathrm{df}=1.957, \mathrm{IFI}=0.918, \mathrm{CFI}=0.916$, and RMSEA $=0.039$. Table 6 demonstrates that a series of the critical ratio of differences was nonsignificant when measurement weights

Table 5 Results of spectral clustering analysis

\begin{tabular}{|c|c|c|c|c|}
\hline Variables (Unit) & $\begin{array}{l}\text { Cluster } 1(N=165) \\
\text { Mean }(\mathrm{SD})\end{array}$ & $\begin{array}{l}\text { Cluster } 2(N=135) \\
\text { Mean }(\mathrm{SD})\end{array}$ & $\begin{array}{l}\text { Cluster } 3(N=204) \\
\text { Mean }(\mathrm{SD})\end{array}$ & $\begin{array}{l}\text { Cluster } 4(N=120) \\
\text { Mean }(\mathrm{SD})\end{array}$ \\
\hline Time Spent on Housework (Hours per day) & $4.120(1.584)$ & $0.960(0.207)$ & $2.200(1.322)$ & $2.000(0.00)$ \\
\hline Time Children Spent Alone (Hours per day) & $0.600(0.847)$ & $0.250(0.436)$ & $4.250(3.489)$ & $0.330(0.473)$ \\
\hline Use of Childcare Support at Home $(0=$ none, $1=$ use $)$ & $0.620(0.486)$ & $0.710(0.455)$ & $0.630(0.485)$ & $0.740(0.440)$ \\
\hline
\end{tabular}


Table 6 Results of the measurement equivalence test for parent groups

\begin{tabular}{lllllllll}
\hline & $\chi^{2}$ & df & IFI & CFI & RMSEA & $\Delta \chi^{2}$ & $\Delta$ df & $p$ \\
\hline Unconstrained model & 1549.884 & 792 & 0.918 & 0.916 & 0.039 & & & \\
Measurements weights & 1580.964 & 840 & 0.919 & 0.918 & 0.038 & 31.080 & 48 & 0.972 \\
Structural weights & 1591.229 & 855 & 0.919 & 0.919 & 0.037 & 41.345 & 63 & 0.984 \\
Structural covariances & 1633.734 & 885 & 0.918 & 0.917 & 0.037 & 83.850 & 93 & 0.741 \\
Structural residuals & 1651.295 & 891 & 0.916 & 0.916 & 0.037 & 101.411 & 99 & 0.414 \\
Measurement residuals & 1772.551 & 957 & 0.910 & 0.910 & 0.037 & 222.667 & 165 & 0.002 \\
\hline
\end{tabular}

(factor loadings), structural weights (regression weights for predicting attitudes and intentions of seeking information), structural covariances (factor variances and covariances), and structural residuals (variances in attitudes and intentions of seeking information) were constrained to be constant across the groups. This result supports the equivalence of the measurement across the parent clusters even though a significant difference was found in the most constrained model, which additionally included measurement residuals to be constant across groups.

The subsequent multigroup analysis revealed that the expectations from the childcare functions of robots that can generate positive parental attitudes toward robots differed from group to group. Table 7 displays that the socialization function of robots was positively associated with parental attitudes toward robots across all groups. No inter-group statistical differences were found in these estimated coefficients for the socialization function. Thus, parents were consistently motivated to use robots to improve their children's social skills regardless of their parenting styles. By contrast, parental expectations from the educational features of robots did not predict parental attitudes in any of the clusters. Additionally, parental expectations from the expert consultation and advisory facilities of robots only exercised a positive effect on the attitudes of parents categorized into the noninterfering cluster $(\beta=0.342, p<0.01)$. Furthermore, the parental desire for entertainment features in robots predicted positive attitudes only in parents designated into the dominant group $(\beta=0.247, p<0.05)$. However, it was confirmed in all clusters that an increase in positive parental attitudes toward robots caused a congruent strengthening of their intent to seek more information about robots.

\subsubsection{Influence of Children's Ages on the Shaping of Parental Attitudes Toward Childcare Robots}

Along with parenting styles, various characteristics of children will affect parents' acceptance of childcare robots. In particular, the second research question (RQ 2) concerned the influence of children's age. To explore how children's age alters parents' expectations regarding each childcare function, a multigroup SEM analysis was

Table 7 Results of the multigroup analysis of parents groups of different parenting styles

\begin{tabular}{|c|c|c|c|c|c|c|c|c|}
\hline \multirow[t]{2}{*}{ Path } & \multicolumn{4}{|c|}{ Family-oriented Parents } & \multicolumn{4}{|c|}{ Work-oriented parents } \\
\hline & $\begin{array}{l}\text { standardized } \\
\text { estimate }\end{array}$ & $\begin{array}{l}\text { unstandard- } \\
\text { ized estimate }\end{array}$ & S. E & C. $\mathrm{R}$ & $\begin{array}{l}\text { standardized } \\
\text { estimate }\end{array}$ & $\begin{array}{l}\text { unstandard- } \\
\text { ized estimate }\end{array}$ & S. E & C. $\mathrm{R}$ \\
\hline Socialization $\rightarrow$ Attitude & $.460 * * *$ & $.592 * * *$ & 0.156 & 3.786 & $.631 * * *$ & $.547 * * *$ & 0.100 & 5.483 \\
\hline Education $\rightarrow$ Attitude & .031 & .031 & 0.137 & 0.224 & .016 & .015 & 0.140 & 0.106 \\
\hline Entertainment $\rightarrow$ Attitude & .086 & .084 & 0.105 & 0.800 & .079 & .078 & 0.114 & 0.682 \\
\hline Expert Consultation $\rightarrow$ Attitude & .159 & .142 & 0.098 & 1.460 & .170 & .132 & 0.082 & 1.615 \\
\hline Attitude $\rightarrow$ Intention to Seek Information & $.752 * * *$ & $.940 * * *$ & 0.105 & 8.940 & $.754 * * *$ & $.909 * * *$ & 0.114 & 7.997 \\
\hline \multirow[t]{2}{*}{ Path } & \multicolumn{4}{|c|}{ Noninterfering parents } & \multicolumn{4}{|c|}{ Dominant parents } \\
\hline & $\begin{array}{l}\text { Standardized } \\
\text { estimate }\end{array}$ & $\begin{array}{l}\text { Unstandard- } \\
\text { ized estimate }\end{array}$ & S. E & C. $\mathrm{R}$ & $\begin{array}{l}\text { standardized } \\
\text { estimate }\end{array}$ & $\begin{array}{l}\text { Unstandard- } \\
\text { ized estimate }\end{array}$ & S. E & C. $\mathrm{R}$ \\
\hline Socialization $\rightarrow$ Attitude & $.306 * *$ & $.301 * *$ & 0.115 & 2.616 & $.368 *$ & $.338 *$ & 0.145 & 2.331 \\
\hline Education $\rightarrow$ Attitude & .004 & .004 & 0.165 & 0.022 & .144 & .167 & 0.225 & 0.741 \\
\hline Entertainment $\rightarrow$ Attitude & .127 & .124 & 0.113 & 1.090 & $.247 *$ & $.206 *$ & 0.095 & 2.170 \\
\hline Expert Consultation $\rightarrow$ Attitude & $.342 * *$ & $.297 * *$ & 0.092 & 3.225 & .072 & .062 & 0.104 & 0.601 \\
\hline Attitude $\rightarrow$ Intention to Seek Information & $.829 * * *$ & $1.046 * * *$ & 0.103 & 10.180 & $.773 * * *$ & $1.027 * * *$ & 0.141 & 7.292 \\
\hline
\end{tabular}

$* p<.05, * * p<.01, * * * p<.001$. 5.3. Exploring differences in children's characteristics 
performed with the early $(N=204)$ and middle $(N=210)$ childhood groups. Parents in each group were raising only one child, specifically aged either three to seven or eight to twelve in Korean age, mainly preschoolers and schoolers. Similar to the previous analysis, a nested comparison test supported the equivalence of measurements across the children's groups (Table 8).

The subsequent multigroup analysis confirmed the differences in parents' expectations between different age groups. As presented in Table 9, robots' entertainment function did not improve parents' attitude in the early childhood group, whereas parents of middle-childhood children were predicted to have a more favorable attitude from the entertainment function $(\beta=0.212, p<0.05)$. Although education function did not significantly influence parents' attitude toward robots in either age group, parents' preference for socialization and expert consultation functions led to more positive attitudes regardless of their children's age. The beta coefficient of the influence of expert consultation on attitude was higher in the middlechildhood group $(\beta=0.316, p<0.01)$ than that in the early childhood group $(\beta=0.240, p<0.01)$, indicating that parents of middle-childhood children may consider robots' expert consultation function to be more crucial.

\subsubsection{Influence of Children's Sibling Status on the Shaping of Parental Attitudes Toward Childcare Robots}

The third research question (RQ 3) explored how the number of children in families changed parents' attitudes toward childcare functions. More specifically, this study investigated whether parents of a single child exhibited a stronger preference for childcare robots. The study data were from 414 single-child families and 210 multi-child families, and a multigroup analysis was conducted to compare these two groups. The configural and metric invariances between groups were confirmed, as presented in Table 10.

The results of the comparison are presented in Table 11. In line with the previous results, the socialization function consistently predicted parents' favorable attitudes in both groups, whereas the education function did not. The most notable difference was in the robots' entertainment function. In the only-child group, parents' expectations of the entertainment function significantly increased their attitude toward robots, indicating that parents raising a single child prefer robots to provide entertainment content $(\beta=0.165$, $p<0.05$ ). By contrast, parents of multiple children did not display such a preference for the entertainment function. This result provides preliminary evidence for the initial assumption that parents of a single child may have a stronger
Table 8 Results of the measurement equivalence test for children's age groups

\begin{tabular}{lllllllll}
\hline & $\chi^{2}$ & df & IFI & CFI & RMSEA & $\Delta \chi^{2}$ & $\Delta$ df & $p$ \\
\hline Unconstrained model & 792.558 & 396 & 0.931 & 0.931 & 0.049 & & & \\
Measurements weights & 809.034 & 412 & 0.931 & 0.93 & 0.048 & 16.476 & 16 & 0.42 \\
Structural weights & 811.679 & 417 & 0.931 & 0.931 & 0.048 & 19.121 & 21 & 0.577 \\
Structural covariances & 826.511 & 427 & 0.93 & 0.93 & 0.048 & 33.953 & 31 & 0.327 \\
Structural residuals & 826.803 & 429 & 0.931 & 0.93 & 0.047 & 34.245 & 33 & 0.408 \\
Measurement residuals & 868.188 & 451 & 0.927 & 0.927 & 0.047 & 75.63 & 55 & 0.034 \\
\hline
\end{tabular}

Table 9 Results of the multigroup analysis of children's age groups

\begin{tabular}{|c|c|c|c|c|c|}
\hline Early childhood group & $\begin{array}{l}\text { Standardized esti- } \\
\text { mate }\end{array}$ & $\begin{array}{l}\text { Unstandardized } \\
\text { estimate }\end{array}$ & S. E & C. $\mathrm{R}$ & $P$ \\
\hline Socialization $\rightarrow$ Attitude & 0.416 & 0.496 & 0.128 & 3.873 & $* * *$ \\
\hline Education $\rightarrow$ Attitude & 0.008 & 0.009 & 0.122 & 0.074 & 0.941 \\
\hline Entertainment $\rightarrow$ Attitude & 0.145 & 0.140 & 0.087 & 1.606 & 0.108 \\
\hline Expert Consultation $\rightarrow$ Attitude & 0.240 & 0.206 & 0.077 & 2.682 & 0.007 \\
\hline Attitude $\rightarrow$ Intention to Seek Information & 0.777 & 0.927 & 0.09 & 10.278 & $* * *$ \\
\hline Middle childhood group & $\begin{array}{l}\text { Standardized esti- } \\
\text { mate }\end{array}$ & $\begin{array}{l}\text { Unstandardized } \\
\text { estimate }\end{array}$ & S. E & C. $\mathrm{R}$ & $P$ \\
\hline Socialization $\rightarrow$ Attitude & 0.414 & 0.466 & 0.116 & 4.002 & $* * *$ \\
\hline Education $\rightarrow$ Attitude & -0.179 & -0.220 & 0.195 & -1.125 & 0.26 \\
\hline Entertainment $\rightarrow$ Attitude & 0.212 & 0.262 & 0.124 & 2.112 & 0.035 \\
\hline Expert Consultation $\rightarrow$ Attitude & 0.316 & 0.306 & 0.116 & 2.648 & 0.008 \\
\hline Attitude $\rightarrow$ Intention to Seek Information & 0.785 & 0.914 & 0.087 & 10.535 & $* * *$ \\
\hline
\end{tabular}


Table 10 Results of the measurement equivalence test for children's sibling status groups

\begin{tabular}{lrlllllll}
\hline & \multicolumn{1}{c}{$\chi^{2}$} & df & IFI & CFI & RMSEA & $\Delta \chi^{2}$ & $\Delta$ df & $p$ \\
\hline Unconstrained model & 948.859 & 396 & 0.938 & 0.938 & 0.047 & & & \\
Measurements weights & 965.833 & 412 & 0.938 & 0.938 & 0.046 & 16.974 & 16 & 0.387 \\
Structural weights & 969.699 & 417 & 0.938 & 0.938 & 0.046 & 20.84 & 21 & 0.469 \\
Structural covariances & 988.007 & 427 & 0.937 & 0.937 & 0.046 & 39.149 & 31 & 0.149 \\
Structural residuals & 993.627 & 429 & 0.937 & 0.936 & 0.046 & 44.769 & 33 & 0.083 \\
Measurement residuals & 1027.895 & 451 & 0.935 & 0.935 & 0.045 & 79.037 & 55 & 0.019 \\
\hline
\end{tabular}

Table 11 Results of the multigroup analysis of children's sibling status groups

\begin{tabular}{|c|c|c|c|c|c|}
\hline Only child group & $\begin{array}{l}\text { Standardized esti- } \\
\text { mate }\end{array}$ & $\begin{array}{l}\text { Unstandardized } \\
\text { estimate }\end{array}$ & S. E & C. $\mathrm{R}$ & $P$ \\
\hline Socialization $\rightarrow$ Attitude & 0.428 & 0.488 & 0.084 & 5.773 & $* * *$ \\
\hline Education $\rightarrow$ Attitude & -0.059 & -0.067 & 0.106 & -0.632 & 0.528 \\
\hline Entertainment $\rightarrow$ Attitude & 0.165 & 0.178 & 0.072 & 2.482 & 0.013 \\
\hline Expert Consultation $\rightarrow$ Attitude & 0.248 & 0.226 & 0.064 & 3.548 & $* * *$ \\
\hline Attitude $\rightarrow$ Intention to Seek Information & 0.775 & 0.910 & 0.063 & 14.547 & $* * *$ \\
\hline Multi-child group & $\begin{array}{l}\text { Standardized esti- } \\
\text { mate }\end{array}$ & $\begin{array}{l}\text { Unstandardized } \\
\text { estimate }\end{array}$ & S. E & C. $\mathrm{R}$ & $P$ \\
\hline Socialization $\rightarrow$ Attitude & 0.487 & 0.410 & 0.094 & 4.387 & $* * *$ \\
\hline Education $\rightarrow$ Attitude & 0.180 & 0.150 & 0.116 & 1.292 & 0.196 \\
\hline Entertainment $\rightarrow$ Attitude & 0.012 & 0.009 & 0.078 & 0.121 & 0.903 \\
\hline Expert Consultation $\rightarrow$ Attitude & 0.157 & 0.124 & 0.066 & 1.880 & 0.060 \\
\hline Attitude $\rightarrow$ Intention to Seek Information & 0.799 & 1.088 & 0.114 & 9.575 & $* * *$ \\
\hline
\end{tabular}

preference for childcare robots because of the lack of parenting time. Parents' expectations of the expert consultation function also differed between the two groups; families of a single child were predicted to prefer the function $(\beta=0.248$, $p<0.001$ ), whereas multi-child families were not. Notably, the beta coefficient was higher in the only-child group than in the multi-child group. Thus, even though the expert consultation function's influence approached significance in the multi-child group, the function should still be prioritized for only-child families.

\subsection{Follow-Up Open-Ended Survey}

Social robots are still in their infancy, and thus, few people have used them. Therefore, in the main questionnaire of this study, only dual-income couples with children were surveyed, but not those who had experience of using social robots. To overcome this limitation, an additional survey was conducted on 23 people who had experience with social robots to investigate their motivations and expectations from such robots. Respondents responded to open-ended survey questions, and a total of 21 respondents' data were analyzed; two respondents' data were excluded because their answers were incomplete. Of the 21 respondents, $73.913 \%$ were women, and they had an average of 1.762 children.
Their average age was 41.429 years, and they worked for an average of $19.763 \mathrm{~h}$ per week, with an average time spent on housework of $2.810 \mathrm{~h}$ on weekdays and $4.725 \mathrm{~h}$ on weekends.

When asked about their motives for using social robots, the respondents' answers included the following: "I am worried that my children cannot meet friends because of COVID-19," "If the robot was like a friend that helps my child's social development, it would be nice," and "I use social robots to understand my child's disposition and aptitude and to know their emotions that day." An analysis of their responses revealed the motivations for using social robots were education, play, the child's disposition, child safety, and consultation with experts. Specifically, the motivation for education (66.666\%), play (42.857\%), grasping the propensity of children $(19.048 \%)$, and socialization (19.048\%) was high. In addition, when asked about their expectations for social robots for children, they gave answers such as, "I think learning is important for children's robots, but it would be nice if they could be a friend to a child alone" and "I would like to give detailed feedback and praise so that the child can be motivated." The analysis revealed that the respondents expected the robot would be convenient to use $(33.333 \%)$ and that it would give children pleasure $(23.810 \%)$. 
The results of the open-ended survey of people with experience with robots supported this study's hypotheses as being well established. As previously mentioned, education, play, and socialization were the most critical motives for parents to consider, and some answered that they wanted consultation with experts, albeit a low proportion $(4.762 \%)$.

\section{Discussion}

\subsection{Summary of the Results}

Figure 3 illustrates the estimated regression coefficients of each childcare function of robots on parents' attitude toward robots by their respective parenting characteristics. As shown in the figure, childcare robots' socialization function was predicted to improve dual-income parents' attitudes across all parenting characteristics. By contrast, none of the parenting characteristics led parents to shape the need for robots' education function. Robots'
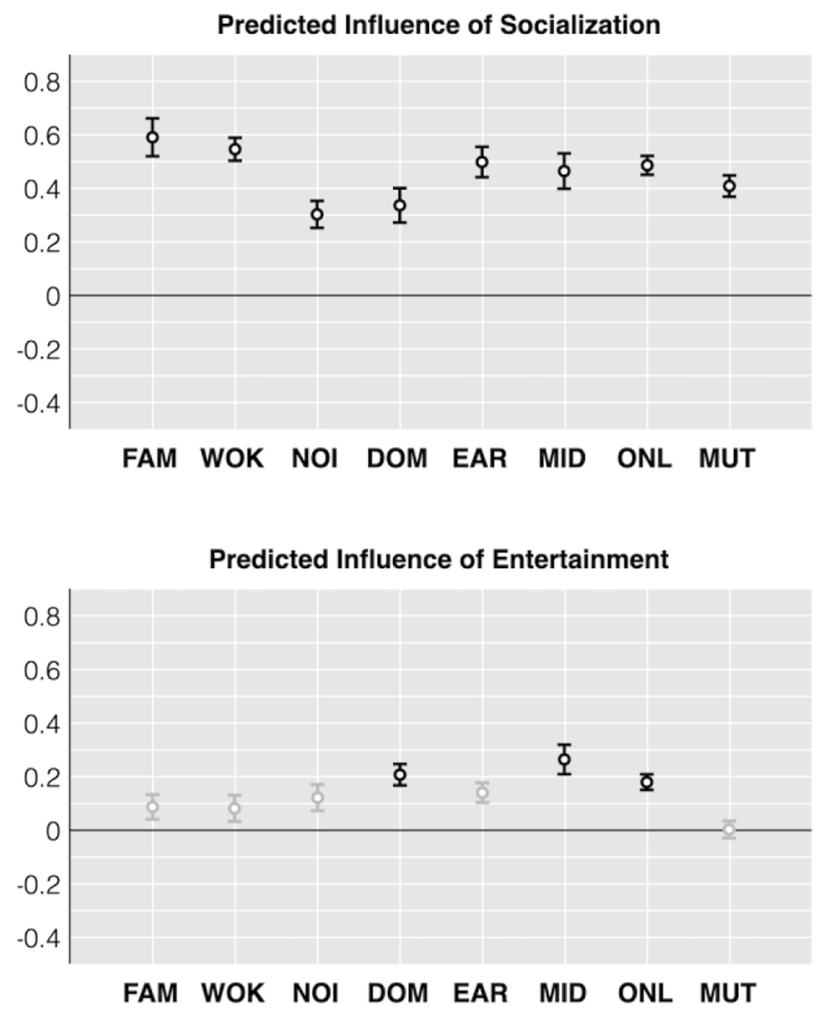

FAM: Family-Oriented Style WOK: Work-Oriented Style NOI: Non-Interfering Style DOM: Dominant Style

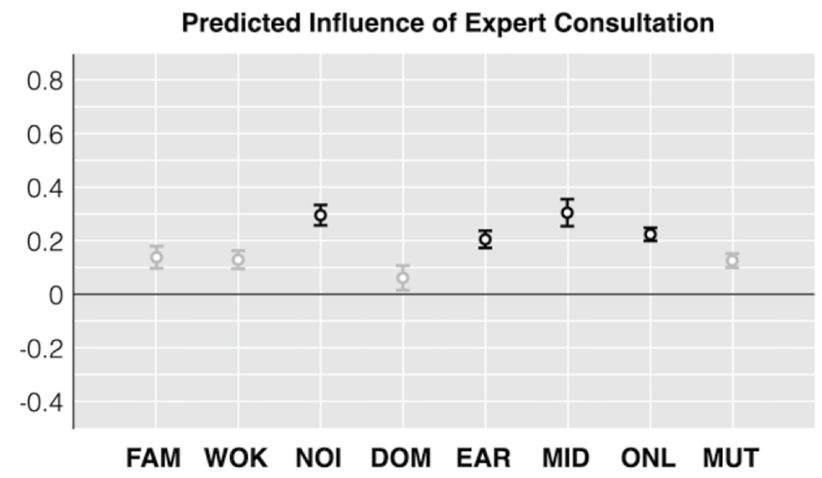

entertainment function was expected to have significant positive influences only for parents with dominant parenting styles, parents who are raising middle-childhood children, and parents of a single child. Finally, robots' expert consultation function was confirmed to improve the attitude of parents with a noninterfering parenting style and those of a single child, as compared with parents with different parenting styles and multiple children. Children's age did not alter the need for the expert consultation function, which exhibited a significant influence for parents of both early- and middle-childhood children.

\subsection{Optimization of Childcare Robots for Different Parenting Styles}

The results of this study indicated that dual-income parents displayed divergent expectations from the parenting-support functions of social robots, which depended on their own parenting styles. This outcome can offer practical implications for companies engaged in devising

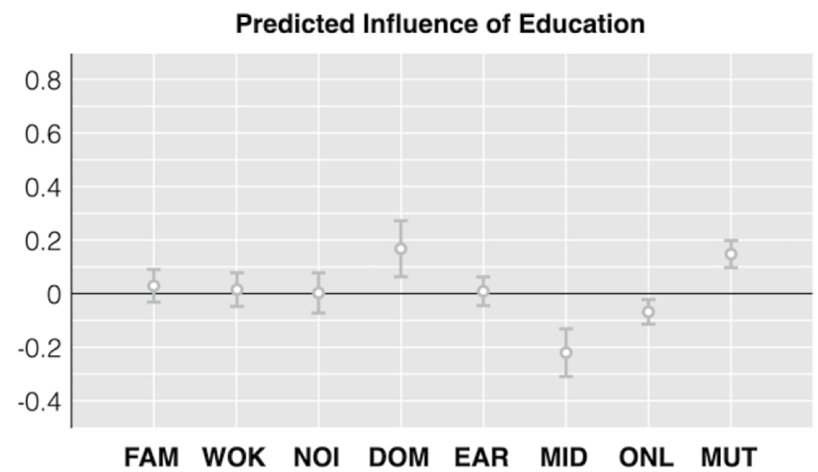

EAR: Early Childhood Group MID: Middle Childhood Group ONL: Only-Child Group MUT: Multi-Children Group
ю Non-Significant Estimates
어 Significant Estimates

Fig. 3 Estimated influences of childcare functions 
marketing strategies for childcare robots by suggesting that markets should be segmented according to distinct parenting needs. Family-oriented parents spent sufficient time on household chores and only demonstrated interest in the social interaction skills of robots that would help to improve the interpersonal skills and ameliorate the socialization of their children. Work-oriented parents were found to actively utilize alternative parenting methods to minimize childcare gaps, and this parenting characteristic is typical of dual-income parents. The economic benefits of dual-income parents allow such family units to avail high-quality parenting services (e.g., nursing) for their children [15]. Like family-oriented parents, work-oriented parents only reported aspirations for the social interaction functions of robots that could aid the enhancement of the interpersonal interaction skills of their children.

Noninterfering and dominant parents reported additional expectations for the functions of childcare robots. Parents in the noninterfering group were predicted to form a positive attitude toward social robots when the products could offer the service of enabling consultations with child development experts. The parents allocated to the dominant group were estimated to exhibit positive attitudes toward social robots when they were programmed to provide engaging entertainment content to children. This incongruous result can be explained by the age difference between the children of parents assigned to the two groups. As children become older, they require less direct nurturing from their parents and are increasingly able to undertake active decision-making roles while their parents are at work. As children mature, their parents are also likely to gain more careerrelated experience and are probably required to perform more responsible workplace roles. The children of parents allocated to the noninterfering group were more than two years older than those of parents assigned to other groups; thus, it is viable that their older children would spend an increased amount of time alone at home. As children are removed from parental supervision, parents tend to desire to become more relevant to their lives, such as through school activities or peers. In fact, one-way analysis of variance and Bonferroni post-hoc analysis results revealed that noninterfering parents exhibited statistically and significantly greater intentions to engage in parenting $[M=3.788, \mathrm{SD}=0.615 ; F(3,620)=5.229$, $p<0.01, \eta_{p}{ }^{2}=0.03$ ] than the other groups (family-oriented: $M=3.588, \mathrm{SD}=0.652$, work-oriented: $M=3.583$, $\mathrm{SD}=0.581$, dominant: $M=3.581, \mathrm{SD}=0.527)$. Therefore, parents in the noninterfering group reported looking forward to the professional counseling functions of robots for their children, which would enable them to make efficient use of their limited parenting time and to better understand the behaviors displayed by their children. On the other hand, the dominant parents anticipated the entertainment features of robots so that their children could be enjoyably engaged while the parents accomplished other chores.

\subsection{Optimization of Childcare Robots with Children's Characteristics}

Children's characteristics also provide implications for the development of childcare robots. For parents of younger children, their expectations for the robot's social interaction function and expert counseling function were predicted to improve their attitudes toward robots. In addition, the robot's ability to provide entertainment content was confirmed to form a positive attitude in parents of older children. This result suggests that the entertainment function of robots should be introduced more carefully when targeting young children. Excessive exposure to video content can hinder the cognitive development of younger children [76], and parents are concerned about the negative effects of media exposure. Therefore, it is recommended that the robot's entertainment function is mainly designed for school children.

The results also indicated that sibling status changes parents' attitudes toward robots. While parents of multiple children formed a positive attitude only for the socialization function of the robot, parents of only children were predicted to respond positively not only to the socialization function of the robot but also to the entertainment and expert counseling functions. This result is consistent with the general perception of parents of only children, namely that they have a tendency to actively search for parenting means to help their child's natural social development. In particular, even multi-child parents demonstrated clear needs for the socialization function of robots. These results suggest that dual-income parents, the subject of this study, can consider childcare robots as a way to provide higher quality social interactions to their children.

\subsection{Implications for Developing Robots' Childcare Functions}

While the socialization function of robots was significant in predicting positive parental attitudes in all four clusters, the educational features did not affect parental attitudes toward robots for any parenting style. These results are particularly noteworthy because numerous studies have validated the educational effects of robots in laboratories and classrooms. The low parental interest in the educational qualities of robots could be explained by the many educational alternatives already available 
to parents from their homes. In fact, classroom robots generally represent only one type of specialized educational equipment. Conversely, parents are likely to prefer diverse educational functions of social robots in their homes. Therefore, the educational features of childcare robots targeted for the home environment must be designed using an approach that differs from the classroom environment. For instance, social robots should participate with children in the accomplishment of their tasks and collaborate with them to achieve task-related goals rather than simply offering access to relevant educational content $[6,22]$. In a meta-analysis of the educational effects of robots, Belpaeme and his colleagues [6] found that only $9 \%$ of the studies utilized robots as colleagues, and not as mere content providers. The results of the present study could promote the scholarly exploration of alternative education-related roles for robots. Above all, this study affirmed that the need for quality social experiences for children was expressed consistently by all parents, regardless of parenting styles. It thus offers the crucial insight that childcare robots should prioritize the development of robots that can engage in natural and socially relevant interactions with children.

\subsection{Limitations of the Study and Suggestions for Future Studies}

Despite the promising results and implications, potential limitations should be acknowledged. First, the survey was administered online, and this mode may not have facilitated the clear iteration of the potential parenting needs with respect to childcare robots. In fact, parents who experienced childcare functions of robots in laboratory environments were reported to develop a more positive attitude toward robots than were those who responded to an online survey that included visuals of robots [14]. Although the open-ended survey supports the findings, the parents who participated in the main study had never used robots; thus, studies with individuals who attain a comprehensive understanding of the usage of robots are likely to identify novel requirements. Second, the parenting styles compared in this study were specifically derived on the basis of behaviors evinced only by the participants of the current investigation. It may be worthwhile for prospective investigations to verify the differences in parental expectations from robots through the classification of more generalized parenting styles. Thus, future researchers are encouraged to systematically compare parental motivations for the use of childcare robots depending on previously devised classifications of parenting styles. Third, the present study surveyed only
Korean parents. Indeed, existing studies have revealed cultural differences in parenting across different cultures. In the West, where individualism is developed, parents raise their children independently, and in the East, where collectivism is prevalent, parents raise their children to be obedient and tolerant [77]. In addition, parents in the East hesitate to leave their children with babysitters, whereas parents in the West use babysitters more commonly [14].

Regarding the limitations, it is noteworthy that recent social development across the world challenges cultural differences. Urbanization increases formal education opportunities [78], and the number of working parents has increased [86, 87], suggesting that parents from different cultures may share similar parenting goals and environments. Recent studies have revealed that Western parents also value etiquette, tolerance, and unselfishness [77], while Eastern parents also emphasize individualistic values, including children's independence and selfreliance $[79,80]$. In this regard, the identified childcare functions may generally contribute to parents' attitude toward social robots. Still, future studies are encouraged to investigate how parents from different cultures exhibit distinctive preferences for respective childcare functions.

\section{Conclusion}

The present study identified social robots' childcare functions that may mitigate dual-income parents' difficulties in raising their children. With a research model based on the U\&G framework, this study investigated how parents' expectations of each childcare function improve their attitude toward social robots. Furthermore, a range of parenting characteristics that alter parents' preferences for childcare functions was explored. The results suggested that social robots can help dual-income parents to raise their children by providing social interaction experiences and entertainment content to them, and by allowing parents to receive consultations from childhood development experts. Indeed, different parenting characteristics, such as parenting styles, children's age, and sibling status, were found to change parents' needs for specific childcare functions, implying that robots can optimize their functions for particular types of families. Thus, the results of the present study will help developers and business practitioners of childcare robots to strategically design and introduce their robots to their target consumer groups. 


\section{Appendix}

\begin{tabular}{|c|c|c|}
\hline Construct & Code & Items \\
\hline \multirow[t]{4}{*}{$\begin{array}{l}\text { Expectation of Socializa- } \\
\text { tion }\end{array}$} & Exp_Soc 1 & $\begin{array}{l}\text { I want robots' ability of } \\
\text { social interaction that can } \\
\text { help children to develop } \\
\text { empathic ability }\end{array}$ \\
\hline & Exp_Soc 2 & $\begin{array}{l}\text { It is important for robots } \\
\text { to support children to } \\
\text { develop their sociality }\end{array}$ \\
\hline & Exp_Soc 3 & $\begin{array}{l}\text { I want robots to encourage } \\
\text { children to be confident in } \\
\text { their social relationships }\end{array}$ \\
\hline & Exp_Soc 4 & $\begin{array}{l}\text { It would be nice if robots } \\
\text { nudged children to } \\
\text { express their own } \\
\text { thoughts and emotions }\end{array}$ \\
\hline \multirow[t]{4}{*}{ Expectation of Education } & Exp_Edu 1 & $\begin{array}{l}\text { I want robots to check } \\
\text { whether children com- } \\
\text { plete their homework }\end{array}$ \\
\hline & Exp_Edu 2 & $\begin{array}{l}\text { It is important for robots to } \\
\text { have a function of sup- } \\
\text { porting children's studies }\end{array}$ \\
\hline & Exp_Edu 3 & $\begin{array}{l}\text { It is important for robots to } \\
\text { supervise children to be } \\
\text { able to study by them- } \\
\text { selves }\end{array}$ \\
\hline & Exp_Edu 4 & $\begin{array}{l}\text { It would be nice if robots } \\
\text { could answer the ques- } \\
\text { tions that children are } \\
\text { curious about }\end{array}$ \\
\hline \multirow[t]{4}{*}{$\begin{array}{l}\text { Expectation of Entertain- } \\
\text { ment }\end{array}$} & Exp_Ent 1 & $\begin{array}{l}\text { I want robots to recommend } \\
\text { entertainment content for } \\
\text { children }\end{array}$ \\
\hline & Exp_Ent 2 & $\begin{array}{l}\text { It is important for robots } \\
\text { to have an entertainment } \\
\text { function that can amuse } \\
\text { children }\end{array}$ \\
\hline & Exp_Ent 3 & $\begin{array}{l}\text { It is important for robots } \\
\text { to know what entertain- } \\
\text { ment content can please } \\
\text { children }\end{array}$ \\
\hline & Exp_Ent 4 & $\begin{array}{l}\text { It would be nice if robots } \\
\text { could play with children } \\
\text { when they are bored }\end{array}$ \\
\hline \multirow[t]{3}{*}{$\begin{array}{l}\text { Expectation of Expert } \\
\text { Consultation }\end{array}$} & Exp_Con 1 & $\begin{array}{l}\text { When necessary, I want to } \\
\text { get parenting consulta- } \\
\text { tions from education } \\
\text { experts by using a robot }\end{array}$ \\
\hline & Exp_Con 2 & $\begin{array}{l}\text { It would be nice if robots } \\
\text { could connect me to child } \\
\text { development experts }\end{array}$ \\
\hline & Exp_Con 3 & $\begin{array}{l}\text { I want to communicate } \\
\text { with child experts using a } \\
\text { robot on various parenting } \\
\text { concerns, including chil- } \\
\text { dren's development and } \\
\text { academic achievement }\end{array}$ \\
\hline
\end{tabular}

\begin{tabular}{|c|c|c|}
\hline Construct & Code & Items \\
\hline \multirow[t]{4}{*}{ Attitude toward Robots } & Attitude 1 & $\begin{array}{l}\text { Social robots give me a } \\
\text { positive feeling }\end{array}$ \\
\hline & Attitude 2 & $\begin{array}{l}\text { I think I will like social } \\
\text { robots }\end{array}$ \\
\hline & Attitude 3 & $\begin{array}{l}\text { By purchasing and using } \\
\text { social robots, I think I can } \\
\text { give a favorable impres- } \\
\text { sion to others }\end{array}$ \\
\hline & Attitude 4 & $\begin{array}{l}\text { Social robots will have a } \\
\text { socially desirable public } \\
\text { image }\end{array}$ \\
\hline \multirow[t]{3}{*}{$\begin{array}{l}\text { Intention to Search Infor- } \\
\text { mation }\end{array}$} & Inf_Seek 1 & $\begin{array}{l}\text { If social robots go on sale, } \\
\text { I will look for more } \\
\text { detailed information about } \\
\text { the robots }\end{array}$ \\
\hline & Inf_Seek 2 & $\begin{array}{l}\text { If social robots go on sale, } \\
\text { I will compare the robots } \\
\text { with other parenting } \\
\text { services }\end{array}$ \\
\hline & Inf_Seek 3 & $\begin{array}{l}\text { If social robots go on sale, } \\
\text { I will search for viable } \\
\text { purchasing options to get } \\
\text { the robots at a reasonable } \\
\text { price }\end{array}$ \\
\hline
\end{tabular}

\section{Declarations}

Conflict of interests The authors declare that they have no conflict of interest.

\section{References}

1. Fong T, Nourbakhsh I, Dautenhahn K (2003) A survey of socially interactive robots. Robot Auton Syst 42:143-166. https://doi.org/ 10.1016/S0921-8890(02)00372-X

2. Feil-Seifer D, Mataric MJ (2005) Defining socially assistive robotics. 9th International Conference on Rehabilitation Robotics, 2005 ICORR 2005 465-468. doi: https://doi.org/10.1109/ICORR.2005. 1501143

3. Lee KM, Jung Y, Kim J, Kim SR (2006) Are physically embodied social agents better than disembodied social agents?: The effects of physical embodiment, tactile interaction, and people's loneliness in human-robot interaction. Int J Hum Comput Stud 64:962-973. https://doi.org/10.1016/j.ijhcs.2006.05.002

4. Fridin M, Belokopytov M (2014) Acceptance of socially assistive humanoid robot by preschool and elementary school teachers. Comput Hum Behav 33:23-31. https://doi.org/10.1016/j.chb. 2013.12.016

5. Li J (2015) The benefit of being physically present_A survey of experimental works comparing copresent robots, telepresent robots and virtual agents. J Hum Comput Stud 77:23-37. https:// doi.org/10.1016/j.ijhcs.2015.01.001

6. Belpaeme T, Kennedy J, Ramachandran A et al (2018) Social robots for education: A review. Sci Robot 3:eaat5954. https://doi. org/10.1126/scirobotics.aat5954 
7. Bainbridge WA, Hart JW, Kim ES, Scassellati B (2010) The Benefits of Interactions with Physically Present Robots over Video-Displayed Agents. Int J of Soc Robotics 3:41-52. https:// doi.org/10.1007/s12369-010-0082-7

8. Jo D, Lee J-G, Lee KC (2014) Empirical analysis of changes in human creativity in people who work with humanoid robots and their avatars. In: Zaphiris P, Ioannou A (eds) Learning and collaboration technologies. Designing and Developing Novel Learning Experiences. Springer, Cham, pp 273-281

9. Belpaeme T, Baxter PE, Read R et al (2013) Multimodal ChildRobot Interaction: Building Social Bonds. J Hum-Robot Interact 1:1-21. https://doi.org/10.5898/JHRI.1.2.Belpaeme

10. Oonaka S (2013) Child-Care Robot and a Method of Controlling the Robot. U.S. Patent No. 8,376,803. Washington, DC: U.S. Patent and Trademark Office.

11. Kahn PH Jr, Gary HE, Shen S (2012) Children's social relationships with current and near-future robots. Child Dev Perspect 7:32-37. https://doi.org/10.1111/cdep.12011

12. Mwangi E, Barakova EI, Diaz M et al (2017) Gaze-based hints during child-robot gameplay. In: Kheddar A, Yoshida E, Sam Ge S, Suzuki K, Cabibihan J-J, Eyssel F, He H (eds) Computer information systems and industrial management. Springer, Cham, pp 413-422

13. Venture G, Indurkhya B, Izui T (2017) Dance with me childrobot interaction in the wild. In: Kheddar A, Yoshida E, Sam Ge S, Suzuki K, Cabibihan J-J, Eyssel F, He H (eds) Computer information systems and industrial management. Springer, Cham, pp 375-382

14. Shiomi M, Hagita N (2017) Social acceptance toward a childcare support robot system: web-based cultural differences investigation and a field study in Japan. Adv Robot 31:1-12. https:// doi.org/10.1080/01691864.2017.1345322

15. Heinrich CJ (2014) Parents“ employment and children"s wellbeing. The Public Opin Q 24:121-146. https://doi.org/10.2307/ 23723386

16. Hsin A, Felfe C (2014) When does time matter? maternal employment, children's time with parents, and child development. Demogr 51:1867-1894. https://doi.org/10.1007/ s13524-014-0334-5

17. Bernal R (2008) The effect of maternal employment and child care on children's cognitive development. Int Econ Rev 49:1173-1209. https://doi.org/10.1111/j.1468-2354.2008. 00510.x

18. Arroyo D, Ishiguro Y, Tanaka F (2017) Design of a Home Telepresence Robot System for Supporting Childcare. In: CSCW '17 Companion. ACM Press, New York, New York, USA, pp 131-134

19. Kwak S, Jung J, Shin E, Kim MS (2008) Design guidelines for childcare robots with an ethnographic studies of dual income and single income. Bull Jpn Soc Sci Des 55:65-74

20. Osada J, Ohnaka S, Sato M (2006) The scenario and design process of childcare robot. PaPeRo Adv Comput Entertain Technol. https://doi.org/10.1145/1178823.1178917

21. Cagiltay B, Ho H-R, Michaelis JE, Mutlu B (2020) Investigating family perceptions and design preferences for an in-home robot. In: IDC '20. ACM, New York, NY, USA, pp 229-242

22. Tanaka F, Matsuzoe S (2012) Children teach a care-receiving robot to promote their learning: field experiments in a classroom for vocabulary learning. J Hum-Robot Interact 1:78-95. https:// doi.org/10.5898/JHRI.1.1.Tanaka

23. Hood D, Lemaignan S, Dillenbourg P (2015) When children teach a robot to write: an autonomous teachable humanoid which uses simulated handwriting. 2015 10th ACM/IEEE International Conference on Human-Robot Interaction (HRI) 83-90. doi: https:// doi.org/10.1145/2696454.2696479

24. Han J, Jo M, Park S, Kim S (2005) The educational use of home robots for children. ROMAN 2005 IEEE International Workshop on Robot and Human Interactive Communication, 2005 378-383. doi: https://doi.org/10.1109/ROMAN.2005.1513808

25. Madnani N, Klebanov BB, Loukina A et al (2019) My turn to read-an interleaved E-book reading tool for developing and struggling readers. ACL. https://doi.org/10.18653/v1/p19-3024

26. Short E, Swift-Spong K, Greczek J, et al (2014) How to train your DragonBot: Socially assistive robots for teaching children about nutrition through play. The 23rd IEEE International Symposium on Robot and Human Interactive Communication 924-929. https://doi.org/10.1109/ROMAN.2014.6926371

27. Abe K, Shiomi M, Pei Y et al (2018) ChiCaRo: tele-presence robot for interacting with babies and toddlers. Adv Robot 32:176190. https://doi.org/10.1080/01691864.2018.1434014

28. Cabibihan J-J, Javed H, Ang M Jr, Aljunied SM (2013) Why robots? a survey on the roles and benefits of social robots in the therapy of children with autism. Int J of Soc Robotics 5:593-618. https://doi.org/10.1007/s12369-013-0202-2

29. Clabaugh C, Becerra D, Deng E et al (2018) Month-long, In-home Case Study of a Socially Assistive Robot for Children with Autism Spectrum Disorder. HRI '18. ACM, New York, NY, USA, pp $87-88$

30. Lin C, MacDorman KF, Šabanović S, et al (2020) Parental Expectations, Concerns, and Acceptance of Storytelling Robots for Children. In: HRI '20. ACM, New York, NY, USA, pp 346-348. doi: https://doi.org/10.1145/3371382.3378376

31. Oros M, Nikolic M, Borovac B, Jerkovic I (2014) Children's preference of appearance and parents' attitudes towards assistive robots*. IEEE-RAS International Conference on Humanoid Robots 2014:360-365. https://doi.org/10.1109/HUMANOIDS. 2014.7041385

32. Burger K (2010) How does early childhood care and education affect cognitive development? An international review of the effects of early interventions for children from different social backgrounds. Early Childhood Research Quarterly 25:140-165. https://doi.org/10.1016/j.ecresq.2009.11.001

33. Chaudry A, Pedroza JM, Sandstrom H, et al (2011) Child Care Choices of Low-Income Working Families. Urban Institute. 2100 M Street NW, Washington, DC 20037. Tel: 202-261-5687; Fax: 202-467-5775; Web site: http://www.urban.org

34. Fiorini M, Keane MP (2014) How the allocation of children's time affects cognitive and noncognitive development. J Law Econ 32:787-836. https://doi.org/10.1086/677232

35. Fox L, Han W-J, Ruhm C, Waldfogel J (2013) Time for children: trends in the employment patterns of parents, 1967-2009. Demogr 50:25-49. https://doi.org/10.1007/s13524-012-0138-4

36. Ruggiero TE (2000) Uses and gratifications theory in the 21st century. Mass Commun Soc 3:3-37. https://doi.org/10.1207/S1532 7825MCS0301_02

37. Luo MM, Remus W (2014) Uses and gratifications and acceptance of Web-based information services: An integrated model. Comput Hum Behav 38:281-295. https://doi.org/10.1016/j.chb.2014.05. 042

38. Park N, Lee KM, Jin S-AA, Kang S (2010) Effects of pre-game stories on feelings of presence and evaluation of computer games. Journal of Human Computer Studies 68:822-833. https://doi.org/ 10.1016/j.ijhcs.2010.07.002

39. Sundar SS, Limperos AM (2013) Uses and grats 2.0: new gratifications for new media. J Broadcast Electron Media 57:504-525. https://doi.org/10.1080/08838151.2013.845827

40. de Graaf MMA, Ben Allouch S (2013) Exploring influencing variables for the acceptance of social robots. Robot Auton Syst 61:1476-1486. https://doi.org/10.1016/j.robot.2013.07.007

41. de Graaf MMA, Ben Allouch S, van Dijk JAGM (2017) Why would $i$ use this in my home? a model of domestic social robot acceptance. Hum-Comput Interact 00:1-59. https://doi.org/10. 1080/07370024.2017.1312406 
42. Tzeng J-Y (2011) Perceived values and prospective users' acceptance of prospective technology: the case of a career eportfolio system. Comput Educ 56:157-165. https://doi.org/10.1016/j.compe du.2010.08.010

43. Leite I, Castellano G, Pereira A et al (2014) Empathic Robots for Long-term Interaction. Int J of Soc Robotics 6:329-341. https:// doi.org/10.1007/s12369-014-0227-1

44. Shiomi M, Nakata A, Kanbara M, Hagita N (2017) A robot that encourages self-disclosure by Hug. In: Kheddar A, Yoshida E, SamGe S, Suzuki K, Cabibihan J-J, Eyssel F, He H (eds) Computer information systems and industrial management. Springer, Cham, pp 324-333

45. Bethel CL, Henkel Z, Stives K, et al (2016) Using robots to interview children about bullying: Lessons learned from an exploratory study. 2016 25th IEEE International Symposium on Robot and Human Interactive Communication (RO-MAN) 712-717. doi: https://doi.org/10.1109/ROMAN.2016.7745197

46. Köse H, Uluer P, Akalın N et al (2015) The effect of embodiment in sign language tutoring with assistive humanoid robots. Int J of Soc Robotics 7:537-548. https://doi.org/10.1007/ s12369-015-0311-1

47. Ajzen I (1991) The theory of planned behavior. Organ Hum Decis Process 50:179-211. https://doi.org/10.1016/0749-5978(91) 90020-T

48. Davis FD (1989) Perceived usefulness, perceived ease of use, and user acceptance of information technology. MIS Q 13:319. https:// doi.org/10.2307/249008

49. Darling N, Steinberg L (1993) Parenting style as context: an integrative model. Dev Psychol Monogr 113:487-496

50. Baumrind D (1971) Current patterns of parental authority. Dev Psychol Monogr 4:1-103. https://doi.org/10.1037/h0030372

51. Baumrind D (1991) The Influence of Parenting Style on Adolescent Competence and Substance Use. J Early Adolesc 11:56-95. https://doi.org/10.1177/0272431691111004

52. Adams G, Tood M (2020) Meeting the school-age child care needs of working parents facing COVID-19 distance learning. Urban Institute

53. Österbacka E, Merz J, Zick CD (2010) Human capital investments in children: A comparative analysis of the role of parent-child shared time in selected countries.

54. Orthner DK, Mancini JA (1990) Leisure impacts on family interaction and cohesion. J Leis Res 22:125-137. https://doi.org/10. 1080/00222216.1990.11969820

55. Shaw SM, Dawson D (2001) Purposive leisure: examining parental discourses on family activities. Leis Sci 23:217-231. https:// doi.org/10.1080/01490400152809098

56. Craig L, Mullan K (2010) Parenthood, gender and work-family time in the united states, australia, italy, france, and denmark. J Marriage Fam 72:1344-1361. https://doi.org/10.1111/j.17413737.2010.00769.x

57. Erikson E (1993) Childhood and Society. Norton \& Company, W. $\mathrm{W}$

58. Coolahan K, Fantuzzo J, Mendez J, McDermott P (2000) Preschool peer interactions and readiness to learn: relationships between classroom peer play and learning behaviors and conduct. Dev Psychol Monogr 92:458-465. https://doi.org/10.1037/00220663.92.3.458

59. Leman PJ, Oldham Z (2005) Do children need to learn to collaborate? Cogn Dev 20:33-48. https://doi.org/10.1016/j.cogdev. 2004.07.002

60. Lemerise EA (1997) Patterns of peer acceptance, social status, and social reputation in mixed-age preschool and primary classrooms. Public Opin Q 43:199-218. https://doi.org/10.2307/23092488

61. Knafo A, Plomin R (2006) Prosocial behavior from early to middle childhood: genetic and environmental influences on stability and change. Dev Psychol 42:771-786. https://doi.org/10.1037/ 0012-1649.42.5.771

62. Saarni C (1988) Children's understanding of the interpersonal consequences of dissemblance of nonverbal emotional-expressive behavior. J Nonverbal Behav 12:275-294. https://doi.org/10.1007/ BF00987596

63. Sommer K, Nielsen M, Draheim M et al (2019) Children's perceptions of the moral worth of live agents, robots, and inanimate objects. J Exp Child Psychol 187:104656. https://doi.org/10. 1016/j.jecp.2019.06.009

64. Sciutti A, Rea F, Sandini G (2014) When you are young, (robot's) looks matter. Developmental changes in the desired properties of a robot friend. In: The 23rd IEEE International Symposium on Robot and Human Interactive Communication. IEEE, pp 567-573. Doi: https://doi.org/10.1109/ROMAN.2014.6926313

65. Martínez-Miranda J, Pérez-Espinosa H, Espinosa-Curiel I et al (2018) Age-based differences in preferences and affective reactions towards a robot's personality during interaction. Comput Hum Behav 84:245-257. https://doi.org/10.1016/j.chb.2018.02. 039

66. Tung F-W (2011) Influence of Gender and Age on the Attitudes of Children towards Humanoid Robots. Springer, Berlin, Heidelberg, Berlin, pp 637-646

67. Shahid S, Krahmer E, Swerts M, Mubin O (2010) Child-robot interaction during collaborative game play-effects of age and gender on emotion and experience. ACM Press, New York, USA, pp 332-335. https://doi.org/10.1145/1952222.1952294

68. Doh H-S, Falbo T (1999) Social competence, maternal attentiveness, and overprotectiveness: only children in Korea. Int J Behav Dev 23:149-162. https://doi.org/10.1080/016502599384044

69. Mellor S (1990) How do only children differ from other children? J Genet Psychol 151:221-230. https://doi.org/10.1080/00221325. 1990.9914656

70. Falbo T, Polit D (1986) Quantitative review of the only child literature: Research evidence and theory development. Dev Psychol Monogr 100:176-198

71. Sweeney JC, Soutar GN (2001) Consumer perceived value: The development of a multiple item scale. J Retail 77:203-220. https:// doi.org/10.1016/s0022-4359(01)00041-0

72. Grewal D, Monroe KB, Krishnan R (1998) The effects of pricecomparison advertising on buyers' perceptions of acquisition value, transaction value, and behavioral intentions. J Mark 62:46. https://doi.org/10.2307/1252160

73. Gefen D, Straub D, Boudreau M-C (2000) Structural equation modeling and regression: guidelines for research practice. CAIS 4:1-78. https://doi.org/10.17705/1CAIS.00407

74. von Luxburg U (2007) A tutorial on spectral clustering. Stat Comput 17:395-416. https://doi.org/10.1007/s11222-007-9033-z

75. James G, Witten D, Hastie T, Tibshirani R (2013) Bias-variance trade-off for K-fold cross-validation. Introd Stat Learn. https://doi. org/10.1007/978-1-4614-7138-7

76. Nathanson AI, Sharp ML, Aladé F et al (2013) The relation between television exposure and theory of mind among preschoolers. J Commun 63:1088-1108. https://doi.org/10.1111/ jcom. 12062

77. Park H, Coello JA, Lau AS (2014) Child socialization goals in east asian versus western nations from 1989 to 2010: evidence for social change in parenting. Parent Sci Pract 14:69-91. https://doi. org/10.1080/15295192.2014.914345

78. Greenfield PM (2009) Linking social change and developmental change: Shifting pathways of human development. Dev Psychol 45:401-418. https://doi.org/10.1037/a0014726

79. Keller H, Lamm B, Abels M et al (2016) Cultural models, socialization goals, and parenting ethnotheories. J Cross Cult Psychol 37:155-172. https://doi.org/10.1177/0022022105284494 
80. Shimizu M, Park H, Greenfield P (2014) Infant sleeping arrangements and cultural values among contemporary Japanese mothers. Front Psychol 5:1-10. https://doi.org/10.3389/fpsyg.2014.00718/ abstract

81. Bianchi S, Robinson J, Milkie M (2006) Changing rhythms of American family life. Russell Sage, New York

82. Azjen I, \& Fishbein M (1980) Understanding attitudes and predicting social behavior. Englewood Cliffs.

83. McCoby E, \& Martin A (1983). Socialization in the context of the family: Parent-child interaction. Handbook of child psychology.

84. Boodman, S. \& Boodman, G. (1995, October 24). The Only child: Lonely or Lucky? The Washington Post. https://www.washington post.com/archive/lifestyle/wellness/1995/10/24/the-only-childlonely-or-lucky/ec6eedc4-d198-4770-abcc-66da9005af27/

85. Milevsky, A. (2015, June 10). Only Child 'Syndrome': How Do Siblings, or a Lack of Them, Affect Your Personality? Independent. https://www.independent.co.uk/life-style/health-and-famil ies/features/only-child-syndrome-how-do-siblings-or-lack-themaffect-your-personality-10309792.html
86. The Pew Research Center, 2015 Pew Research Center. (2015. November 4). Raising Kids and Running a Household: How Working Parents Share the Load. <https://www.pewsocialtrends. org/2015/11/04/raising-kids-and-running-a-household-how-worki ng-parents-share-the-load/> Retrieved 20.10.08.

87. The Pew Research Center, 2015 Pew Research Center. (2015. December 17). The American family today. <https://www. pewsocialtrends.org/2015/12/17/1-the-american-family-today/> Retrieved 20.10.08.

88. Kahn PH, Kanda T, Ishiguro H et al (2012) "Robovie, you 'll have to go into the closet now": children's social and moral relationships with a humanoid robot. Dev Psychol 48:303-314. https:// doi.org/10.1037/a0027033

Publisher's Note Springer Nature remains neutral with regard to jurisdictional claims in published maps and institutional affiliations. 